\title{
Antibiotic Therapy of Infections Due to Pseudomonas aeruginosa in Normal and Granulocytopenic Mice: Comparison of Murine and Human Pharmacokinetics
}

\author{
Andreas U. Gerber, Hans-Peter Brugger, \\ Charlotte Feller, Tomas Stritzko, and Beat Stalder
}

\author{
Department of Medicine, Inselspital and Institute of \\ Medical Microbiology, University of Bern, \\ Bern, Switzerland
}

\begin{abstract}
An effort was made to elucidate the limits of drug-activity tests in small animals. Human plasma kinetics of gentamicin, netilmicin, ticarcillin, ceftazidime, and ceftriaxone were approximated in normal and in granulocytopenic mice infected with various strains of Pseudomonas aeruginosa in the thigh muscle or intraperitoneally. The effect of such dosing on bacterial time-kill curves and on survival was compared with the effect of identical amounts of drug given as a single-bolus injection. With $\beta$-lactams, a highly significant superiority of fractionated dosing (simulated human kinetics) over bolus injections (murine plasma kinetics) was demonstrated, whereas with aminoglycosides it was a singlebolus injection that tended to be more active. Thus, when tested in conventional smallanimal models, aminoglycoside activity may be overestimated, whereas $\beta$-lactam activity may be underestimated in respect to humans. These differences found in vivo most probably reflect the different pharmacodynamics between aminoglycosides and $\beta$-lactam drugs (time-kill curves, dose-response curves, and postantibiotic effect) similar to those previously observed in vitro.
\end{abstract}

In a first approach, the in vivo activity and toxicity of any new drug is routinely studied in experimental models by using small animals such as mice, rats, guinea pigs, or rabbits. Moreover, some measure of the activity and toxicity of a single dose has become a mandatory requirement for any new drug to be licensed. Although conclusions from such studies are not directly transferable to man, they are at least looked on as a basis for investigations to be performed in more expensive animal models or humans. However, major biologic differences have to be considered between small experimental animals and man, one of which is metabolic activity in general. This difference becomes most evident in a compari-

Received for publication 1 April 1985, and in revised form 29 July 1985 .

This work was supported by grants $3.865-0.81$ and $3.907-0.83$ from the Swiss National Foundation for Scientific Research and grant Forsch. 210.AK.82(1) from the Swiss League against Cancer.

Portions of this work were presented at the 23rd Interscience Conference on Antimicrobial Agents and Chemotherapy, Las Vegas, Nevada, October 1983 [abstract 363]; at the 13th International Congress of Chemotherapy, Vienna, Austria, August 1983 [abstracts SS 4.2/16-2 and PS 5.2/1.7]; and at the Fourth Mediterranean Congress of Chemotherapy, Rhodes, Greece, October 1984 [abstract 65].

Please address requests for reprints to Dr. A. U. Gerber, Department of Medicine, University Hospital of Bern, CH-3010 Bern, Switzerland. son of human vs. small-animal kinetics of many injected drugs. As an example, we found a plasma halflife in mice of $15 \mathrm{~min}$ for penicillin G [1], of 16-20 min for ticarcillin, and of $22 \mathrm{~min}$ for gentamicin [2, 3]. In contrast, the half-lives in humans for these drugs are known to be $\sim 0.5,1.2$, and $2 \mathrm{hr}$ for penicillin G, ticarcillin, and gentamicin, respectively [4, 5]. These differences in half-life may explain the very poor results frequently obtained in small-animal models, even with antimicrobial agents that have been shown to be very potent in vitro against the target organism. Thus, compared with man, much higher doses of antimicrobial agents have to be given to small animals to obtain antimicrobial efficacy.

The present study was based on the hypothesis that the difference between small animals and man regarding drug kinetics cannot be overcome by just injecting larger amounts (per kilogram of body weight) of that substance into small animals. Rather, some kind of "human-adapted" pharmacokinetics of the study drug should be approximated in small animals.

In a tentative pioneering effort we used an experimental thigh infection - as well as the standard mouse peritonitis model - to elucidate the impact of murine vs. human half-life of $\beta$-lactam drugs and aminoglycosides on activity against $P$ seudomonas aeruginosa. In one group of mice the study drug was given as a single-bolus injection that was followed 
by typical murine plasma kinetics of the drug, i.e., very high peak levels and a half-life in the order of 15-25 min. In a comparative group of mice the same total amount of study drug was subdivided and injected as fractional doses such that human plasma kinetics of the drug were approximated. Antimicrobial activity was quantitated by construction of bacterial time-kill curves in vivo. For better assessment of the antimicrobial activity of the drug per se the studies were performed not only in normal animals but in granulocytopenic animals as well.

\section{Materials and Methods}

Organisms. A clinical isolate of $P$. aeruginosa designated A10 was the main study organism. Two strains of $P$. aeruginosa were included in confirmatory studies: strain ATCC 27853 (ATCC, Rockville, $\mathrm{Md})$ and an additional clinical isolate, designated 14974. Clinical isolates were from the Institute of Medical Microbiology (Bern, Switzerland). In addition, Escherichia coli strain ATCC 25922 was used to study ceftriaxone dynamics. All organisms were susceptible to the study drugs when tested by the method of Bauer et al. [6] in vitro. MICs and MBCs in vitro were determined by using the broth-dilution technique [7] and Mueller-Hinton broth supplemented with $\mathrm{Ca}^{++}$and $\mathrm{Mg}^{++}$, as suggested by Stratton and Reller [8].

Drugs. Drugs used for the in vitro determination of MICs and MBCs were standard powders. Ticarcillin was obtained from Beecham Laboratories (Betchworth, Surrey, U.K.); gentamicin and netilmicin from Essex AG (Lucerne, Switzerland); ceftazidime from Glaxo Pharmaceuticals (Greenford, Middlesex, U.K.); and ceftriaxone from Hoffmann La Roche (Basel, Switzerland). Drugs used for in vivo studies were commercial products: cyclophosphamide (Mead Johnson Pharmaceuticals, Evansville, Ind), gentamicin and netilmicin (Essex), ticarcillin (Beecham), ceftazidime (Glaxo), and ceftriaxone (Roche).

Mice. Female ICR mice weighing 27-30 g each were obtained from Tierzucht der Universität (Tierspital, Zürich, Switzerland). Granulocytopenia was produced as previously reported [2], i.e., by two ip injections of cyclophosphamide, 150 and $100 \mathrm{mg} / \mathrm{kg}$, at four days and one day, respectively, before the mice were infected. Smears from blood and infected thighs were checked for the presence of granulocytes in some but not all experiments.
Determinations of plasma drug levels. Blood was drawn from the retroorbital sinus into heparinized microhematocrit tubes (Clay Adams, Parsippany, NY). A biologic assay [9] using Bacillus subtilis strain ATCC 6633 (Difco, Detroit) for gentamicin, netilmicin, and ticarcillin, and E. coli strain ATCC 25922 for ceftazidime and ceftriaxone was performed for the determination of plasma drug concentrations. Standard curves were obtained in pooled ICR-mouse plasma.

Preliminary experiments had shown that peak drug levels in plasma were obtained by $10-15 \mathrm{~min}$ after sc injections of the study drug. Thus, in main experiments, peak drug levels were drawn 15 min after the first drug injection.

Bacterial inocula. Broth cultures of the study organisms were grown to $\sim 10^{8} \mathrm{cfu} / \mathrm{ml}$ (estimated by turbidity, as determined in separate experiments). Before injection, the study organisms were washed in ice-cold $0.9 \% \mathrm{NaCl}$ and resuspended in $0.9 \% \mathrm{NaCl}$ to a concentration of $10^{8} \mathrm{cfu} / \mathrm{ml}$.

Quantitation of bacterial growth and killing. Amputated thighs were immediately homogenized with a Polytron ${ }^{\circledR}$ tissue homogenizer (Kinematica, Lucerne, Switzerland) in $4 \mathrm{ml}$ of iced saline $(8.5 \mathrm{~g}$ of $\mathrm{NaCl} /$ liter, $50 \mathrm{mg}$ of $\mathrm{Ca}^{++} /$liter, $200 \mathrm{mg}$ of $\mathrm{Mg}^{++} / \mathrm{li}-$ ter) to which $0.1 \mathrm{ml}$ of $\beta$-lactamase (Whatman Biochemicals, Maidstone, Kent, U.K.) was added. Homogenates were plated in duplicate on trypticsoy agar (Becton Dickinson) plates. After 15-18 hr of incubation, the numbers of cfu were counted and mathematically transformed into remaining viable organisms per thigh.

Experimental design in vivo. Thigh infection model. Two hours before starting the treatment, 0.1 $\mathrm{ml}$ of an ice-cold suspension of $10^{8} \mathrm{cfu}$ of $P$. aerugi$n o s a / \mathrm{ml}$ in $0.9 \% \mathrm{NaCl}$ was injected into the thigh of slightly ether-anesthetized granulocytopenic or normal mice. Two groups of mice were treated comparatively with one of two regimens in each experiment. (I) a single sc bolus injection of the study drug (in $0.1 \mathrm{ml}$ of $0.9 \% \mathrm{NaCl}$ ) followed by repeated injections of $0.9 \% \mathrm{NaCl}$ and (2) an identical total amount of the same study drug subdivided into fractional decreasing doses and injected sc every $15 \mathrm{~min}$ (ticarcillin), every $20 \mathrm{~min}$ (gentamicin, netilmicin, or ceftazidime), or every $30 \mathrm{~min}$ (ceftriaxone). Control mice received repeated injections of $0.9 \% \mathrm{NaCl}$ instead of the study drug, as did the mice treated according to the first regimen. In each experiment, blood was drawn every 20-60 min from at least three 

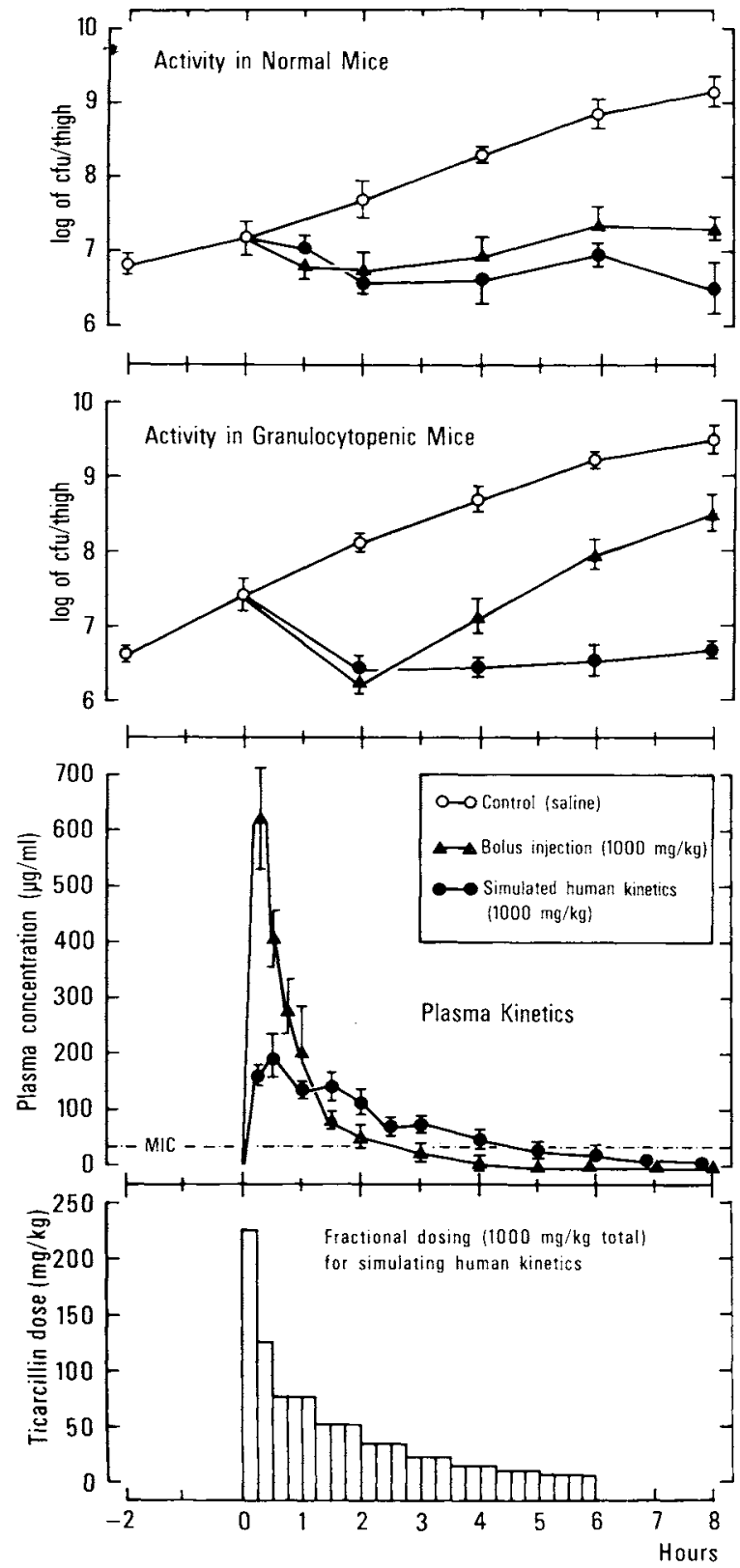

Figure 1. Human vs. murine plasma kinetics of ticarcillin and activity against $P$. aeruginosa A10 in vivo. Each data point in growth and kill curves (top and center top) represents the geometric mean value of three to five mice $\pm 1 \mathrm{SD}$. Data points in center bottom panel stand for the mean value $\pm 1 \mathrm{SD}$ of plasma level determinations from three to six mice (compiled from experiments shown in top and center top panels). Open columns (bottom) show the fractional doses injected sc at $15 \mathrm{~min}$ intervals. mice for determination of drug levels. Blood sampling was devised such that no more than a total of two blood samples (plus a final one just prior to killing) were drawn from each mouse during the experiment.

At various intervals, three to six mice per sampling point were killed for the quantification of remaining organisms per thigh.

Peritonitis model. A standard inoculum of $15-20$ times the $\mathrm{LD}_{50}$ of washed organisms was injected ip with $3 \%$ hog mucin into normal female ICR mice. Mice were observed and deaths were recorded at 12-hr intervals for at least seven days. Modes of treatment and dosage intervals were exactly as in the thigh infection model.

Evaluation of results and statistics. Except when otherwise mentioned, the comparison of antimicrobial efficacy of the two modes of drug administration was based on experiments performed with the same bacterial inoculum on the same day and injected into randomly allotted mice. Results were evaluated by using the two-tailed $t$ test for unpaired samples [10].

The $\mathrm{LD}_{50}$ of $P$ aeruginosa, as determined in the peritonitis model, and the calculation of the $50 \%$ curative dose $\left(\mathrm{CD}_{\mathrm{so}}\right)$ were performed according to Reed and Muench [11].

\section{Results}

Granulocytopenia. Previous studies had shown that cyclophosphamide, given at doses used in the main experiments, resulted in complete agranulocytosis and left $<50$ granulocytes $/ \mathrm{mm}^{3}$ in peripheral blood [2]. In main experiments, we checked for granulocytopenia in blood smears from 5-10 mice chosen at random. No more than three granulocytes per smear could be found in such samples.

Efficacy studies with $\beta$-lactam drugs in the thigh infection model. Figure 1 shows the method of simulating human pharmacokinetics and also the impact of drug kinetics (half-life in mice vs. simulated human model) on the efficacy of ticarcillin against $P$. aeruginosa.

A single-bolus injection of $1,000 \mathrm{mg}$ of ticarcil$\mathrm{lin} / \mathrm{kg}$ resulted in peak plasma levels (drawn at 15 min after injection) of $610 \mu \mathrm{g} / \mathrm{ml}$. At $\sim 2 \mathrm{hr}$ after bolus injection, ticarcillin levels fell below the MIC for $P$. aeruginosa A10 $(32 \mu \mathrm{g} / \mathrm{ml})$. Fractional dosing of ticarcillin resulted in a simulated half-life of $71 \mathrm{~min}$, and measurable drug levels were found up to $6 \mathrm{hr}$ 
after starting the treatment. Areas under the curve (AUCs) were similar for both modes of dosing (529 and $538 \mu \mathrm{g} \mathrm{hr} / \mathrm{ml}$ after bolus injection and fractional dosing, respectively).

In saline-treated control mice, $P$. aeruginosa $\mathrm{A} 10$ grew at a $\log$ linear rate. An inoculum of $\sim 10^{7} \mathrm{cfu}$ invariably killed normal mice between 12 and $24 \mathrm{hr}$ after infection, and all untreated granulocytopenic mice were killed by the infection shortly after $12 \mathrm{hr}$.

In normal mice, we found a small but statistically significant $(P<.05)$ superiority of drug plasma kinetics over a single bolus injection in the simulated human model. Breakthrough growth did not occur, although plasma drug levels fell below the MIC at 2.5 and $4.8 \mathrm{hr}$ after bolus injection and initiation of simulated human kinetics, respectively.

In granulocytopenic mice (figure 1), plasma drug kinetics clearly dictated not only the time course of the bactericidal effect but equally the therapeutic outcome. After bolus injection, significant $(P<.001)$ bacterial regrowth occurred as soon as the ticarcillin level fell below the MIC, whereas no such breakthrough was observed in mice treated with this drug by simulated human kinetics. Almost identical results to those shown in figure 1 were obtained in confirming experiments with $P$. aeruginosa strain ATCC 27853 treated with ticarcillin $(1,000 \mathrm{mg} / \mathrm{kg})$.

The activity of ceftazidime $(250 \mathrm{mg} / \mathrm{kg}$ in granulocytopenic mice) against $P$. aeruginosa ATCC 27853 was determined in an additional set of experiments (figure 2). As found with ticarcillin, the superiority of simulated human kinetics over bolus injection was highly significant.

Additional experiments were performed with ceftriaxone. A poorly ceftriaxone-susceptible $P$. aeruginosa strain (A10; MIC, $16 \mu \mathrm{g} / \mathrm{ml}$ ) and a highly susceptible $E$. coli (ATCC 25922; MIC, $0.5 \mu \mathrm{g} / \mathrm{ml}$ ) were chosen as target organisms (figure 3). Each mouse was infected with $P$. aeruginosa in one thigh and with $E$. coli in the opposite thigh. A total dose of ceftriaxone was chosen that, with both modes of drug administration and throughout the duration of the experiment, guaranteed drug levels above the MIC for $E$. coli but not for that of $P$. aeruginosa after bolus injection. As shown in figure 3 , the time course of the antimicrobial effect against $E$. coli ATCC 25922 was identical for both modes of dosing, a result indicating that the activity of this drug was mainly determined by the aggregate time the levels of this drug stayed above the MIC for the target organisms. $P$. aeruginosa was also similarly affected by both
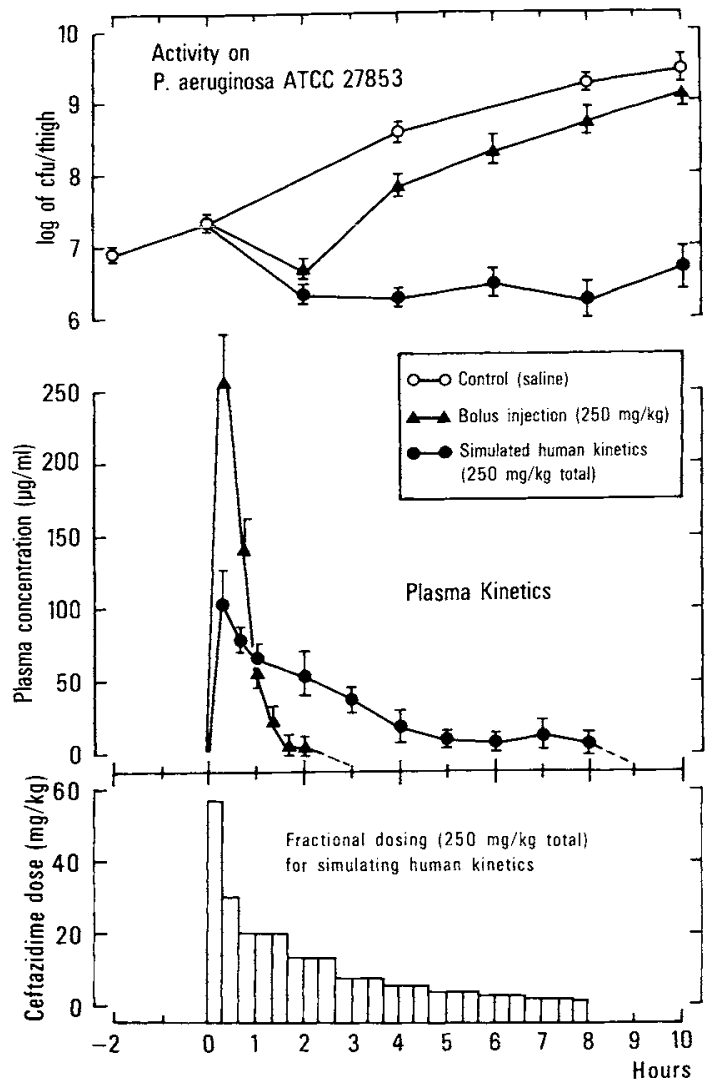

Figure 2. Human vs. murine plasma kinetics of ceftazidime and activity on $P$. aeruginosa ATCC 27853 in granulocytopenic mice. Plasma levels fell below the MIC $(2 \mu \mathrm{g} / \mathrm{ml})$ by $\sim 3$ and $7 \mathrm{hr}$ after bolus and fractional dosing, respectively. See figure 1 for explanation of symbols.

modes of dosing during the first $4 \mathrm{hr}$ of treatment. In sharp contrast to $E$. coli, however, $P$. aeruginosa started to regrow in mice treated by bolus injection of the drug. This breakthrough growth could well be explained by the fact that, $4 \mathrm{hr}$ after bolus injection, the drug levels fell below the MIC. Approximated human pharmacokinetics of ceftriaxone, on the other hand, prevented drug levels falling below the $\mathrm{MIC}$ and, as a consequence, prevented bacterial breakthrough growth.

Efficacy studies with aminoglycosides in the thigh infection model. The impact of plasma kinetics on the activity of gentamicin against $P$. aeruginosa in vivo is shown in figure 4. Again, normal and granulocytopenic host animals were studied. Gentamicin (32 $\mathrm{mg} / \mathrm{kg}$ ) injected in decreasing fractional doses was used to approximate peak plasma levels and kinetics as obtained after maximal dosing in man. This 

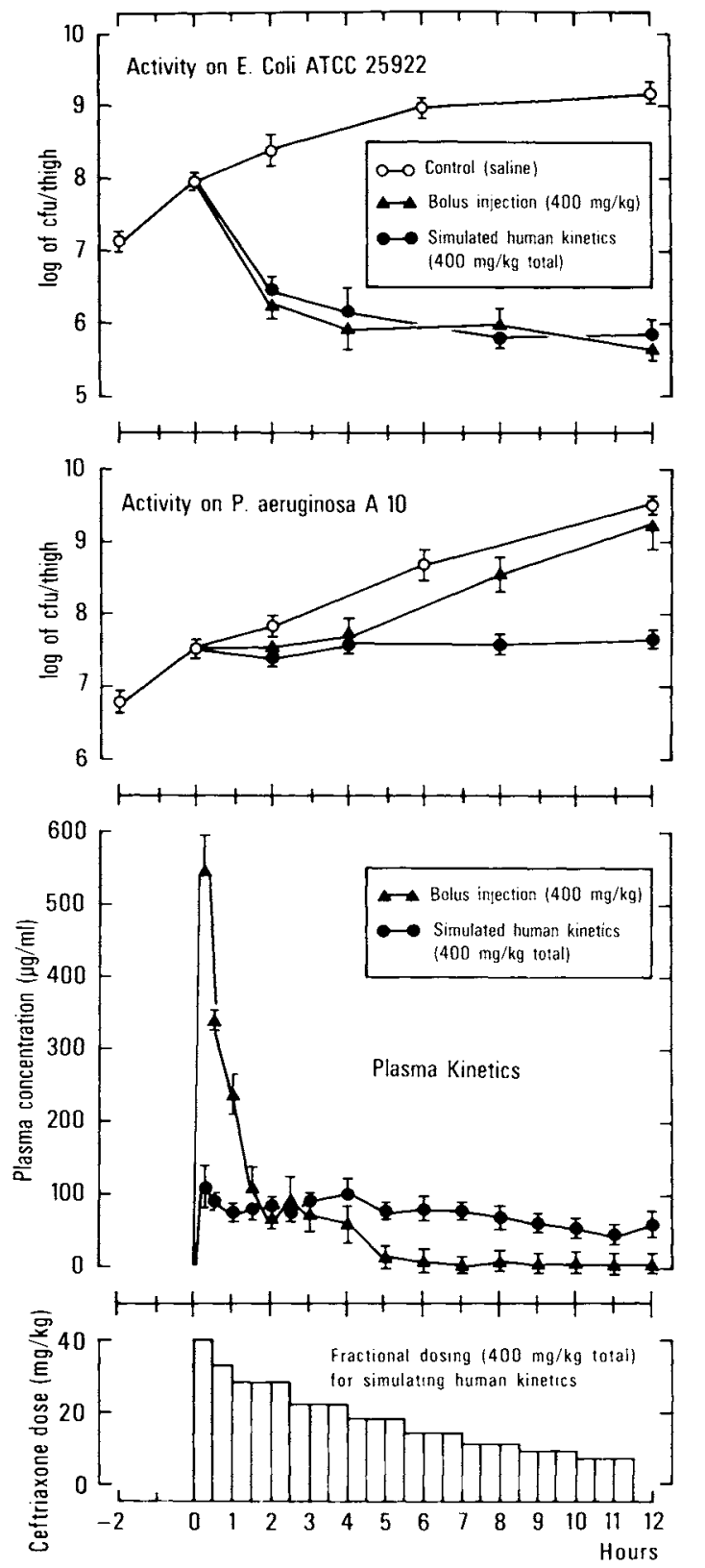

Figure 3. Human vs. murine plasma kinetics of ceftriaxone and activity against $E$. coli and $P$. aeruginosa. See figure 1 for explanations of symbols.

regimen was thus compared with that in which 32 $\mathrm{mg} / \mathrm{kg}$ was given as a single-bolus injection.

Bolus injection of gentamicin resulted in peak plasma levels that exceeded the MIC for the target organisms $(8 \mu \mathrm{g} / \mathrm{ml})$ for $\sim 1.5 \mathrm{hr}$ followed by a halflife (based on plasma levels of the first $2 \mathrm{hr}$ ) of 20.4 $\min$. A long $\lambda$ phase was observed. In contrast, fractional dosing of the same total amount of drug led to a simulated half-life of $112 \mathrm{~min}$. The total AUC was $35.8 \mathrm{mg} \mathrm{hr} / \mathrm{ml}$ and $42.6 \mathrm{mg} \mathrm{hr} / \mathrm{ml}$ after bolus and fractional dosing, respectively.

The time course of the bactericidal effect of the two dosing modes of gentamicin differed substantially from the one previously obtained with $\beta$-lactams. In normal and in granulocytopenic mice, bolus injection was significantly more effective at 1 and $2 \mathrm{hr}$ of treatment $(P<.01)$. Later on, however, this difference became considerably smaller. Repeated experiments were necessary to demonstrate a significant difference $(P<.0125)$ in normal mice when the drug-isodose point $(8 \mathrm{hr})$ was reached, i.e., the time when equal total amounts of gentamicin had been injected in both groups of mice. On the other hand, in granulocytopenic animals no superiority of the bolus injection could be demonstrated by the time the isodose point was reached. This loss of superiority was mainly due to late breakthrough growth of the target organisms.

A series of confirming experiments was performed with netilmicin and three strains of $P$. aeruginosa. Again the effect of approximated human plasma kinetics of the study drug (obtained by decreasing fractional doses) was compared with the effect of a single bolus injection. Results obtained in granulocytopenic mice are shown in figure 5.

Netilmicin exhibited a clear gentamicin-type response. As with gentamicin, the time course of the bactericidal effect was markedly dependent on peak plasma levels (superiority of bolus injections after $1 \mathrm{hr}$ of treatment). At the isodose point, however, both modes of treatment proved to be equally effective in all three strains tested.

Efficacy studies in the mouse peritonitis model. Focusing on ticarcillin, ceftazidime, and netilmicin and on P. aeruginosa ATCC 27853, the mouse peritonitis model was used to further assess the impact of bolus vs. simulated human kinetics on antimicrobial efficacy. Mice were infected with 15 to $20 \mathrm{LD}_{50}$ (5 $\times 10^{7} \mathrm{cfu} / \mathrm{ml}$ ) ip. One hour later groups of 12 mice were treated with drug doses that varied from an ineffective to a $100 \%$ effective (i.e., death-preventing) dose. In the very same experiment each dose was given as a single bolus injection in one group of mice vs. fractional doses of the same total amount of drug resulting in approximated human plasma kinetics in a comparative group.

In contrast to netilmicin, ticarcillin $(\leqslant 900 \mathrm{mg} / \mathrm{kg})$ 
was unable to prevent death of infected animals when a single-bolus injection or a single course of fractional doses was given. Similarly, ceftazidime $(1,000$ $\mathrm{mg} / \mathrm{kg}$ ) had no death-preventing effect when injected as one bolus and saved only $33 \%$ of infected animals when administered in decreasing fractional doses over $8 \mathrm{hr}$. Therefore, two bolus injections of ticarcillin and ceftazidime were compared with two courses of fractional dosing over $6 \mathrm{hr}$ and $8 \mathrm{hr}$, respectively. Results are listed in table 1 . Clearly, as shown before in the thigh infection model, ticarcillin and ceftazidime were significantly more effective when administered in fractional doses (simulated human plasma kinetics). In contrast, bolus injections proved to be superior to fractional doses of netilmicin. Moreover, animals that died after treatment with $\beta$-lactams did so significantly earlier when treated by conventional methods than when treated by simulated human pharmacokinetics. On the other hand, netilmicin-treated mice died later when treated by conventional bolus injection rather than by simulated human pharmacokinetics.

Drug kinetics of single bolus injections and single 6- to 8-hr courses of simulated human kinetics were studied in separate experiments. The time after starting the treatment was calculated when drug concentrations fell below the MIC level for the target organism. After bolus injection and fractional dosing, respectively, this time was 2 and $5 \mathrm{hr}$ for ticarcillin $(900 \mathrm{mg} / \mathrm{kg}), 2$ and $8 \mathrm{hr}$ for ceftazidime ( 250 $\mathrm{mg} / \mathrm{kg}$ ), and $<1 \mathrm{hr}$ for both modes of treatment with netilmicin $(6.7 \mathrm{mg} / \mathrm{kg})$.

\section{Discussion}

In two animal models, we clearly demonstrated the relation between half-life and antimicrobial activity of various drugs. In normal and granulocytopenic mice, a given dose of a $\beta$-lactam drug (ticarcillin, ceftazidime, or ceftriaxone) had a poor effect on $P$. aeruginosa when injected as a single bolus. In contrast, a highly significant superiority was found when the same total amount of these drugs was subdivided and administered in fractional doses so that human plasma kinetics were approximated. On the other hand, two aminoglycosides (gentamicin and netilmicin) proved to be equally or even more effective when administered as a bolus injection than when human pharmacokinetics were approximated with an identical amount of these drugs. Thus, in vivo, the activity of gentamicin and netilmicin was more

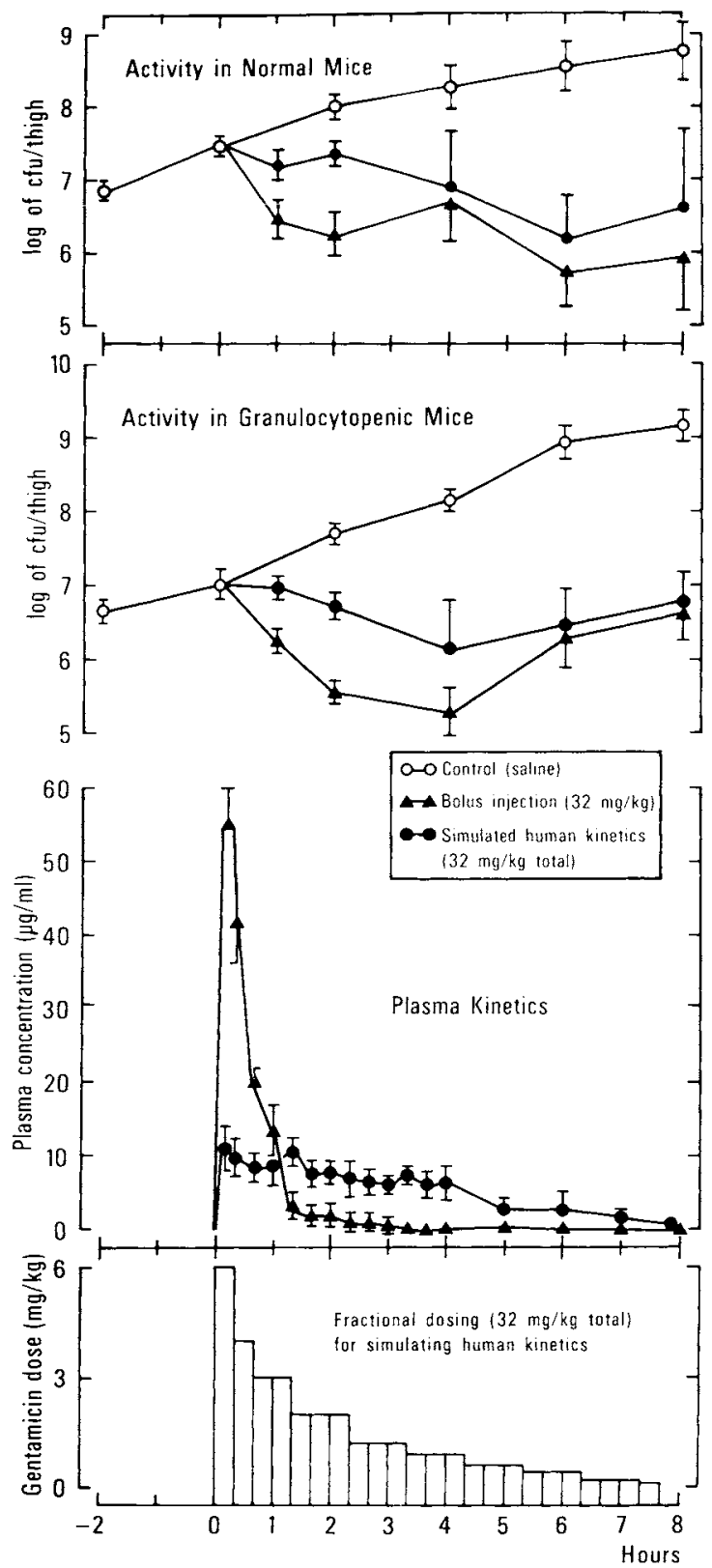

Figure 4. Human vs. murine plasma kinetics of gentamicin and activity in normal and granulocytopenic mice against $P$. aeruginosa strain A10. Mean values $\pm 1 \mathrm{SD}$ from three to 12 animals per data point.

likely to be peak-level dependent, whereas the activity of ticarcillin, ceftazidime, and ceftriaxone depended mainly on the time of persisting drug levels.

It is most evident that both dose and half-life, which mainly determine the AUC of a parenterally given drug, are of key importance for the activity 


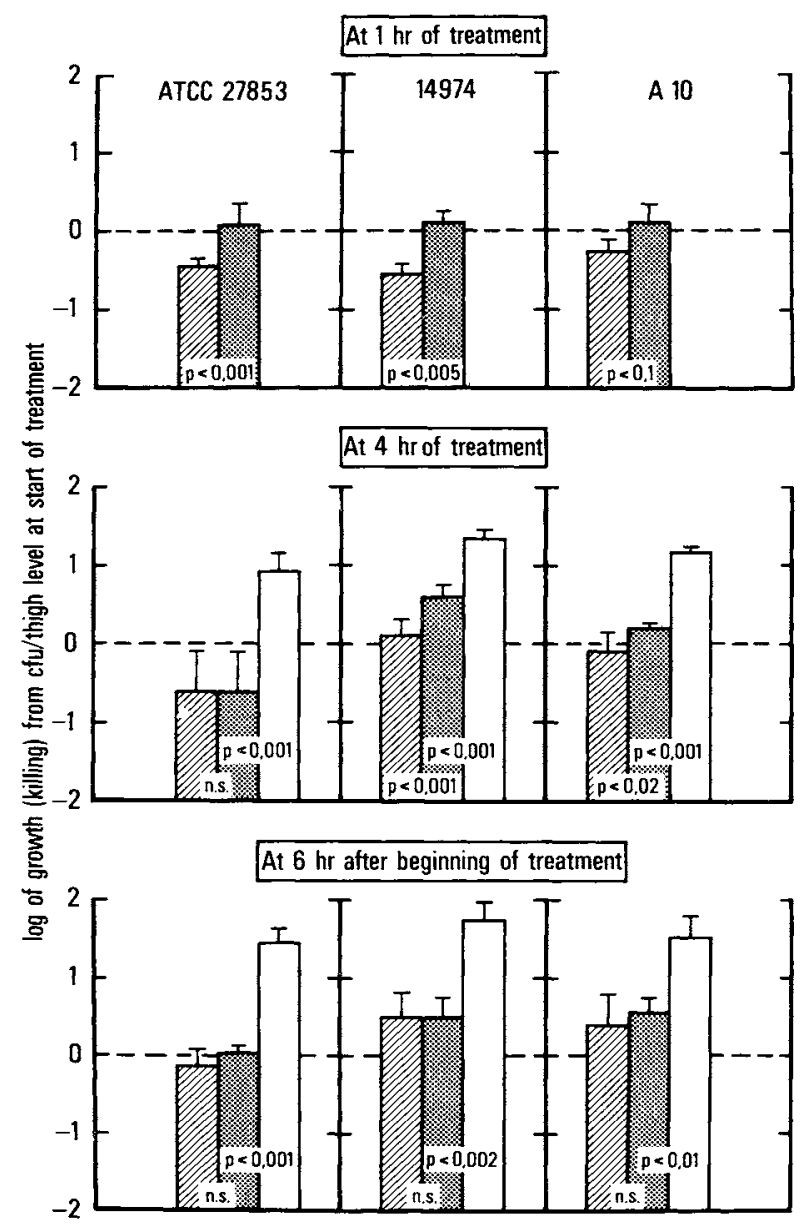

Figure 5. Human vs. murine plasma kinetics of netilmicin and activity against three different strains of $P$. aeruginosa in granulocytopenic mice. Bars represent geometric means of three to 12 mice \pm SD of the $\Delta-\log$ from cfu/thigh level at start of treatment (total dose, 28 $\mathrm{mg} / \mathrm{kg}$ ): hatched bars, bolus injection (peak level of 32.9 $\pm 6 \mu \mathrm{g} / \mathrm{ml}$ followed by a half-life of $22.1 \mathrm{~min}$ ); dotted bars, fractional dosing resulting in peak levels of $10.4 \pm$ $1.7 \mu \mathrm{g} / \mathrm{ml}$ followed by a half-life of $119 \mathrm{~min}$; open bars, untreated controls. Standard MICs were 4,8 , and $8 \mu \mathrm{g} / \mathrm{ml}$ for strain ATCC 27853, 14974, and A10, respectively.

of an antibiotic in vivo. The present study demonstrates that in addition to the AUC per se it is the shape of the AUC that may have a considerable impact on antimicrobial activity in vivo. Moreover, the effect of the shape of the AUC (ESAUC) proved to depend on the drug in question. This finding in turn most likely relates to the mechanism of action and more specifically to the shape of the dose-response curve of the drugs. We have previously shown that the bactericidal effect of gentamicin and netilmicin on Pseudomonas is fast and drug-concentration de- pendent in vitro as well as in our animal model [12]. The dose-response curve of gentamicin on Pseudomonas had no ceiling $[12,13]$. In contrast, the bactericidal effect of various $\beta$-lactam drugs against $P$. aeruginosa clearly had an upper limitation that was close to the MIC, i.e., the bactericidal activity of $\beta$-lactams was not dose dependent in concentrations above the MIC [14]. Those findings indicate that - in contrast to aminoglycosides - any dosing and dosage schedule of $\beta$-lactam drugs that results in high-spiking blood levels far above the MIC for short periods of time is actually wasting the drug.

Preliminary results of ongoing studies in our laboratory indicate that the difference in ESAUC between ticarcillin, ceftazidime, and ceftriaxone, on one hand, and gentamicin and netilmicin, on the other hand, is characteristic for $\beta$-lactam drugs (ticarcillintype response) and aminoglycosides (gentamicintype response) in general. Moreover, on the basis of extended previous work with the same study organisms [14], we postulate that the ESAUC can be derived, at least in part, from in vitro time-kill and regrowth curves and from in vitro concentrationresponse curves of a given combination of drug and organism [14].

The results of our present study are in full agreement with results of previous investigations by both ourselves and others. On the basis of sound experimental work it has been postulated that the activity of $\beta$-lactam drugs on organisms other than Pseudomonas depends also on the aggregate time the drug level stays above the MIC $[15,16]$. In addition, no substantial postantibiotic effect (PAE; i.e., suppression of bacterial growth after removal of the drug) could be demonstrated for $\beta$-lactam drugs against gram-negative organisms [17]. This lack of a PAE may be an additional factor that explains the poor efficacy of bolus injections of $\beta$-lactam antibiotics in the present study. On the other hand, aminoglycosides have been shown to exhibit a PAE of up to $2 \mathrm{hr}$ on $P$. aeruginosa in vitro and in vivo [2, $13,17]$. Thus, the PAE may cover, at least in part, the dosage interval and prevent bacterial breakthrough growth.

In the present study, a PAE was again observed after bolus injection of gentamicin. However, in granulocytopenic animals, this PAE was not long enough to prevent regrowth of the target organisms up to the isodose point. On the other hand, no breakthrough growth was observed in normal animals. This difference between granulocytopenic and normal mice can well be explained by results of recent 
Table 1. Impact of dosage schedule on $\mathrm{CD}_{50}$ of three drugs against $P$. aeruginosa ATCC 27853 in mice.

\begin{tabular}{|c|c|c|}
\hline \multirow[b]{2}{*}{ Drug } & \multicolumn{2}{|c|}{$\mathrm{CD}_{50}$} \\
\hline & Bolus injection & Fractional dosing \\
\hline Ticarcillin & $2 \times 750 \mathrm{mg} / \mathrm{kg}$ & $2 \times 450 \mathrm{mg} / \mathrm{kg}$ \\
\hline Ceftazidime & $2 \times 550 \mathrm{mg} / \mathrm{kg}$ & $2 \times 250 \mathrm{mg} / \mathrm{kg}$ \\
\hline Netilmicin & $1 \times 6 \mathrm{mg} / \mathrm{kg}$ & $1 \times 13.4 \mathrm{mg} / \mathrm{kg}$ \\
\hline
\end{tabular}

studies. A synergistic effect of various antibiotics and the activity of granulocytes has been demonstrated $[18,19]$. In addition, a so-called postantibiotic leukocyte effect has recently been described for some drugs [20], i.e., an enhanced susceptibility of drugpreexposed organisms to killing and phagocytosis by granulocytes. Thus, in normal, as opposed to granulocytopenic hosts, breakthrough growth of bacteria may be suppressed by granulocyte synergy below the MIC and postantibiotic leukocyte effect.

There is no question that due to ease of handling and economic aspects, mice and rats must remain the chief experimental animals for preclinical studies. We have to consider, however, that because of the very active metabolism and the very short half-life of antimicrobial agents in small animals, results obtained with any test substance in such animal models cannot easily be scaled up to man, even if the difference regarding pharmacokinetics is taken into account. Rather, it should be kept in mind thatbesides the AUC - the shape of the AUC is a relevant additional factor that determines the pharmacological response to antimicrobial agents and probably to any other test substance in vivo. We believe, therefore, that misleading results may be obtained if a biologically active substance is tested in small animals only after injections at intervals of many hours, similar to those used in man. Since the extent and even the quality of the ESAUC is different for different drugs with different dose-response curves, caution must be urged, especially for comparisons of drugs so performed.

\section{References}

1. Gerber AU, Bundtzen RW, Craig WA. Effect of dosing regimens on the activity of antimicrobial agents in an in vivo model. In: Periti P, Gialdroni Grassi G, eds. Current chemotherapy and immunotherapy. Vol I. Washington, DC: American Society for Microbiology, 1982:124-6

2. Gerber AU, Vastola AP, Brandel J, Craig WA. Selection of aminoglycoside-resistant subpopulations of Pseudomonas aeruginosa in a in vivo model. J Infect Dis 1982;146:691-7

3. Gerber AU, Craig WA, Brugger H-P, Feller C, Vastola AP, Brandel J. Impact of dosing intervals on activity of gentamicin and ticarcillin against Pseudomonas aeruginosa in granulocytopenic mice. J Infect Dis 1983;147:910-7

4. Parry MF, Pancoast SJ. Antipseudomonal penicillins. In: Ristuccia AM and Cunha BA, eds. Antimicrobial therapy. New York: Raven Press, 1984:197-207

5. Ristuccia AM. Aminoglycosides. In: Ristuccia AM and Cunha BA, eds. Antimicrobial therapy. New York: Raven Press, 1984:305-28

6. Barry AL, Thornsberry C. Susceptibility testing: Diffusion test procedures. In: Lennette EH, Balows A, Hausler WJ, Jr., and Truant JP, eds. Manual of clinical microbiology. 3rd ed. Washington, D.C.: American Society for Microbiology, 1980:463-74

7. Gavan TL, Barry AL. Microdilution test procedures. In: Lennette EH, Balows A, Hausler WJ, Jr., and Truant JP eds. Manual of clinical microbiology. 3rd ed. Washington, D.C.: American Society for Microbiology, 1980:459-62

8. Stratton CW, Reller LB. Serum dilution test for bactericidal activity. I. Selection of physiologic diluent. J Infect Dis 1977;136:187-95

9. Sabath LD, Anhalt JP. Assay of antimicrobics. In: Lennette EH, Balows A, Hausler WJ, Jr., and Truant JP eds. Manual of clinical microbiology. 3rd ed. Washington, D.C.: American Society for Microbiology, 1980:485-90

10. Snedecor GW, Cochran WG. Statistical methods. 6th ed. Ames, Iowa: Iowa State University Press, 1967

11. Reed LJ, Muench H. A simple method of estimating fifty percent endpoints. Am J Hyg 1938;27:493-7

12. Gerber AU, Feller-Segessenmann C. In vivo assessment of in vitro killing patterns of Pseudomonas aeruginosa. J Antimicrob Chemother 1985;15[Suppl A]:201-6

13. Gerber AU, Wiprächtiger P, Stettler-Spichiger U, Lebek G. Constant infusions vs. intermittent doses of gentamicin against Pseudomonas aeruginosa in vitro. J Infect Dis 1982;145:554-60

14. Gerber AU, Feller C, Brugger HP. Time course of the pharmacological response to beta-lactam antibiotics in vitro and in vivo. Eur J Clin Microbiol 1984;3:592-7

15. Eagle H, Fleishman R, Musselman A. Effect of schedule of administration on the therapeutic efficacy of penicillin. Importance of aggregate time penicillin remains at effectively bactericidal levels. Am J Med 1950;9:280-99

16. Craig W. Pharmacokinetic and experimental data on betalactam antibiotics in the treatment of patients. Eur J Clin Microbiol 1984;3:575-8

17. Bundtzen RW, Gerber AU, Cohn DL, Craig WA. Postantibiotic suppression of bacterial growth. Rev Infect Dis 1981;3:28-37

18. Root RK, Isturiz R, Molavi A, Metcalf JA, Malech HL. Interactions between antibiotics and human neutrophils in the killing of Staphylococci. Studies with normal and cytochalasin B-treated cells. J Clin Invest 1981;67:247-59

19. Lorian V, Atkinson B. Bactericidal effect of polymorphonuclear neutrophils on antibiotic-induced filaments of gram-negative bacilli. J Infect Dis 1984;149:719-27

20. Prool H, McDonald PJ. Enhancement of leukocyte activity against Escherichia coli after brief exposure to chloramphenicol. Antimicrob Agents Chemother 1979;16:695-700 